\title{
Locality of Chlorophyll-A Distribution in the Intensive Study Area of the Ariake Sea, Japan in Winter Seasons based on Remote Sensing Satellite Data
}

\author{
Kohei Arai 1 \\ 1 Graduate School of Science and Engineering \\ Saga University \\ Saga City, Japan
}

\begin{abstract}
Mechanism of chlorophyll-a appearance and its locality in the intensive study area of the Ariake Sea, Japan in winter seasons is clarified by using remote sensing satellite data. Through experiments with Terra and AQUA MODIS data derived chlorophyll-a concentration and truth data of chlorophyll-a concentration together with meteorological data and tidal data which are acquired for 6 years (winter 2010 to winter 2015), it is found that strong correlation between the chlorophyll-a concentration and tidal height changes. Also it is found that the relations between ocean wind speed and chlorophyll-a concentration. Meanwhile, there is a relatively high correlation between sunshine duration a day and chlorophyll-a concentration. Furthermore, it is found that there are different sources of chlorophyll-a in the three different sea areas of Ariake Sea area in the back, Isahaya bay area, and Kumamoto offshore area.
\end{abstract}

Keywords-chlorophyl-a concentration; red tide; diatom; solar irradiance; ocean winds; tidal effect

\section{INTRODUCTION}

The Ariake Sea is the largest productive area of Nori (Porphyra yezoensis1) in Japan. In winters of 2012 and 2013, a massive diatom bloom occurred in the Ariake Sea, Japan [1]. In case of above red tides, bloom causative was Eucampia zodiacus 2 . This bloom has being occurred several coastal areas in Japan and is well reported by Nishikawa et al. for Harimanada sea areas [2]-[10]. Diatom blooms have recurrently occurred from late autumn to early spring in the coastal waters of western Japan, such as the Ariake Sea [11] and the Seto Inland Sea [12], where large scale "Nori" aquaculture occurs. Diatom blooms have caused the exhaustion of nutrients in the water column during the "Nori" harvest season. The resultant lack of nutrients has suppressed the growth of "Nori" and lowered the quality of "Nori" products due to bleaching with the damage of the order of billions of yen [3].

\footnotetext{
${ }_{2}^{1}$ http://en.wikipedia.org/wiki/Porphyra

http://www.eos.ubc.ca/research/phytoplankton/diatoms/centric/eucampia/e_zo diacus.html
}

This bloom had been firstly developed at the eastern part of the Ariake Sea. However, as the field observation is timeconsuming, information on the developing process of the red tide, and horizontal distribution of the red tide has not yet been clarified in detail. To clarify the horizontal distribution of red tide, and its temporal change, remote sensing satellite data is quite useful.

In particular in winter, almost every year, relatively large size of diatoms of Eucampia zodiacus appears in Ariake Sea areas. That is one of the causes for damage of Porphyra yezoensis. There is, therefore, a strong demand to prevent the damage from Nori farmers. Since 2007, Asteroplanus karianus appears in the Ariake Sea almost every year. In addition, Eucampia zodiacus appears in Ariake Sea since 2012. There is a strong demand on estimation of relatively large size of diatoms appearance, size and appearance mechanism).

The chlorophyll-a concentration algorithm developed for MODIS $^{3}$ has been validated [13]. The algorithm is applied to MODIS data for a trend analysis of chlorophyll-a distribution in the Ariake Sea area in winter during from 2010 to 2015 is made. Then chlorophyll-a distributions of three specific areas, Ariake Bay, Isahaya Bay and Kumamoto Offshore are compared. It is intended to confirm that the sources of the chlorophyll-a concentration are different each other of sea areas.

The major influencing factors of chlorophyll-a concentration are species, sea water temperature (sunshine duration a day), northern winds for convection of sea water, and tidal effect have to be considered. Therefore, the relations between chlorophyll-a concentration and tidal effects, ocean wind speed as well as sunshine duration a day are, then, clarified.

In the next section, the method and procedure of the experimental study is described followed by experimental data and estimated results. Then conclusion is described with some discussions.

\footnotetext{
${ }^{3}$ http://modis.gsfc.nasa.gov/
} 


\section{METHOD AND PROCEDURE}

\section{A. The Procedure}

The procedure of the experimental study is as follows,

1) Gather MODIS data of the Ariake Sea areas together with the chlorophyll-a concentration estimation with the MODIS data,

2) Compare chlorophyll-a distribution of three different sea areas, Ariake Bay, Isahaya Bay and Kumamoto Offshore,

3) Gather the meteorological data which includes sunshine duration a day, ocean wind speed and direction, tidal heights,

4) Correlation analysis between MODIS derived chlorophyll-a concentration and geophysical parameters, ocean wind speed, sunshine duration a day, tidal heights is made.

\section{B. The Intensive Study Areas}

Fig.1 shows the intensive study areas in the Ariake Sea area, Kyushu, Japan.

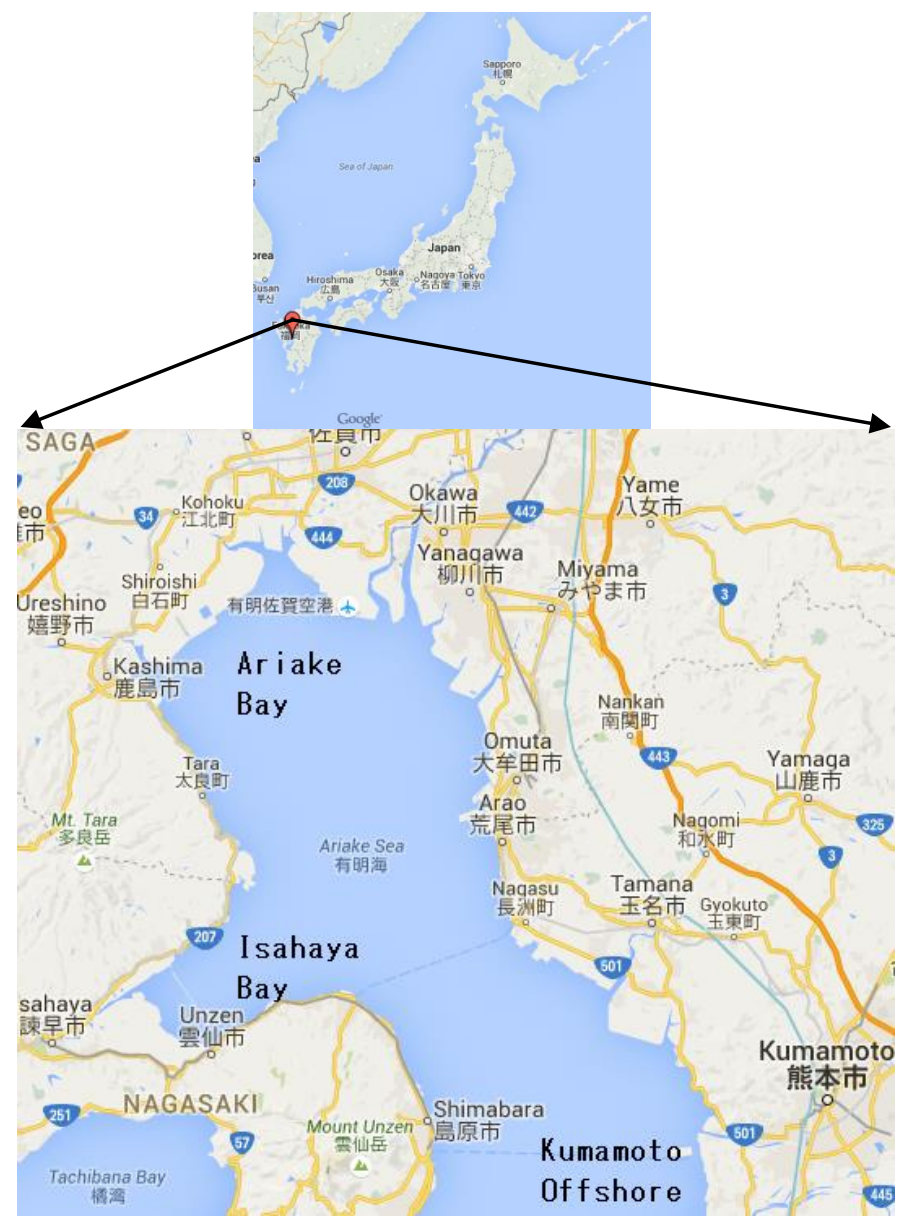

Fig. 1. Intensive study areas

\section{EXPERIMENTS}

\section{A. The Data Used}

MODIS derived chlorophyll-a concentrations which area acquired for the observation period of one month (January) in
2010 to 2015 are used for the experiments. Also, the meteorological data which includes sunshine duration a day, ocean wind speed and direction, tidal heights which are acquired for the same time periods as MODIS acquisitions mentioned above. In particular for 2015, two months January and February) data are used for trend analysis. Fig. 2 shows the data used for two month period of time series MODIS derived chlorophyll-a concentrations in January and February, 2015. These data are acquired on January $4,6,7,8,9,9^{4}, 10,12,17$, 18, 20, 23, February 1, 3, 6, 9, 13, 14, 20, 27, and March 2 in 2015, respectively (from top left to bottom right in Fig.2). MODIS data are acquired on these days. MODIS data cannot be acquired on the rest of days due to cloudy condition. White portions in the chlorophyll-a concentration images are cloud covered areas.
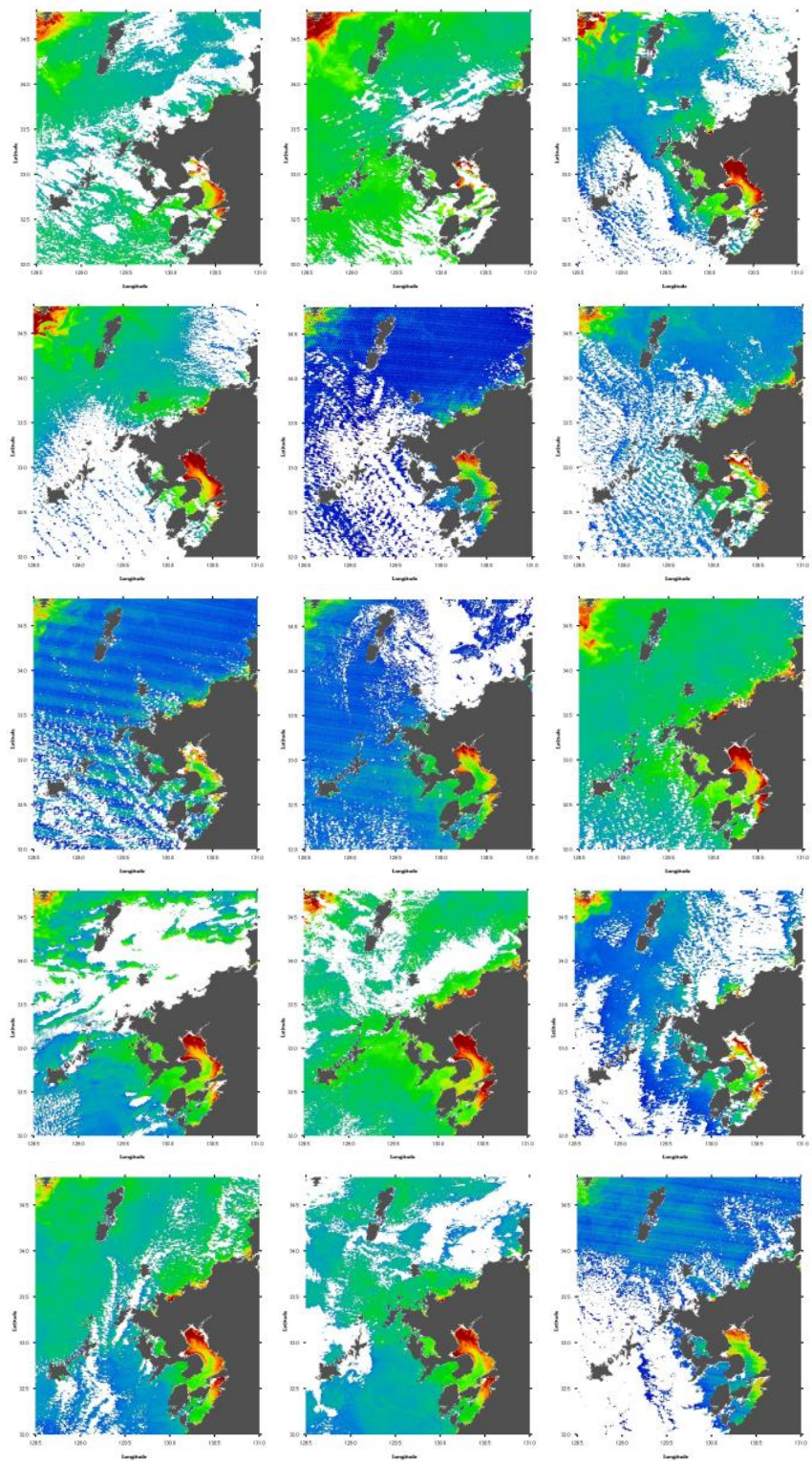

\footnotetext{
${ }^{4}$ There are two satellites which carry MODIS instruments, Terra and AQUA. Two MODIS data derived chlorophyll-a concentrations can be acquired occasionally.
} 

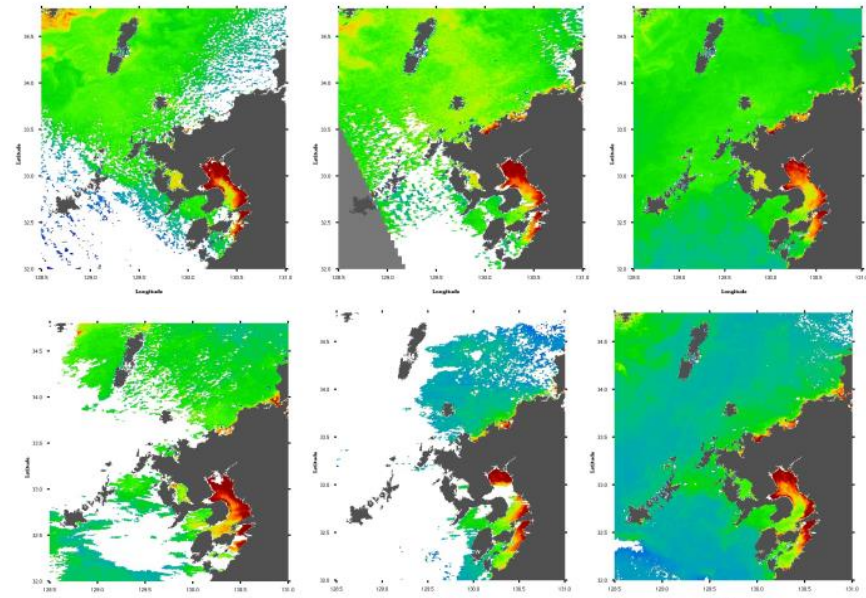

Fig. 2. MODIS data derived chlorophyll-a distribution in 2015

This time frame is red tide (Phytoplankton) blooming period. Such this MODIS derived chlorophyll-a concentration data are available almost every day except cloudy and rainy conditions.

Blooming is used to be occurred when the seawater becomes nutrient rich water, calm ocean winds, long sunshine duration after convection of seawater (vertical seawater current from the bottom to sea surface). Therefore, there must are relations between the geophysical parameters, ocean wind speed, sunshine duration, tidal heights and chlorophyll-a concentration.

As shown in Fig.2, it is clear that the diatom appeared at the back in the Ariake Sea, Ariake Bay and is not flown from somewhere else. Also, there is relatively low chlorophyll-a concentration sea areas between Isahaya Bay and Ariake Bay. Therefore, chlorophyll-a concentration variations are isolated each other (Isahaya Bay and Ariake Bay).

Fig.3 to Fig.7 also shows MODIS data derived chlorophyll-a concentrations in January 2014, 2013, 2012, 2011 and 2010, respectively. MODIS data are acquired on January 10, 13, 15, 16, 19, 23, 24, 26, 27, 29, 30 and February 4, respectively (from top left to bottom right in Fig.3).
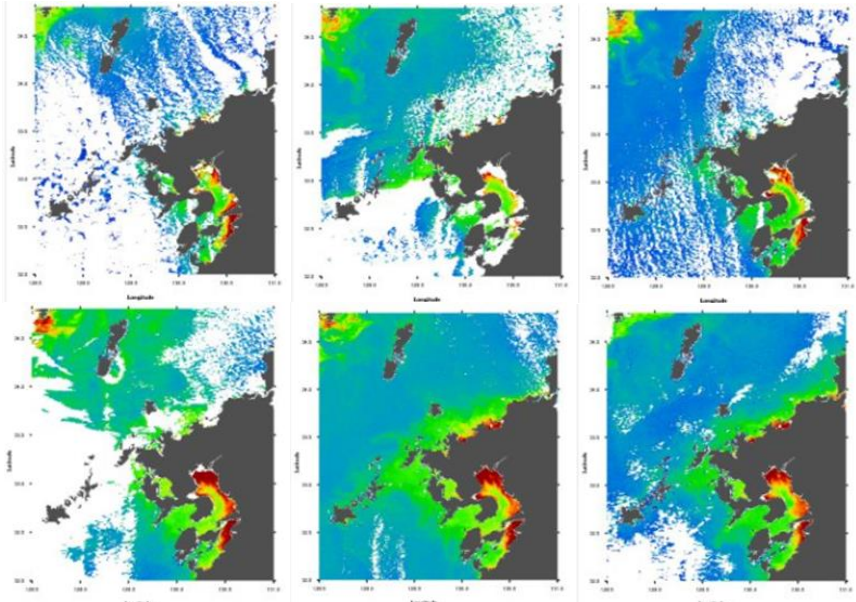
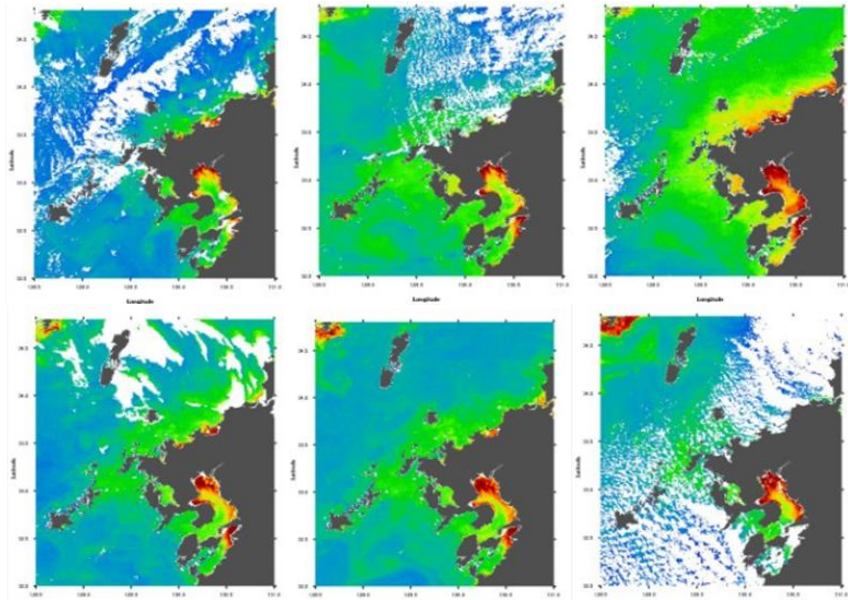

Fig. 3. MODIS data derived chlorophyll-a concentrations in 2014

Fig.4 shows the time series of MODIS data derived chlorophyll-a concentrations in 2013. MODIS data are acquired on January 4, 6, 10, 12, 15, 18, 19, 25, 28, 30, and 31, respectively (from top left to bottom right in Fig.4).
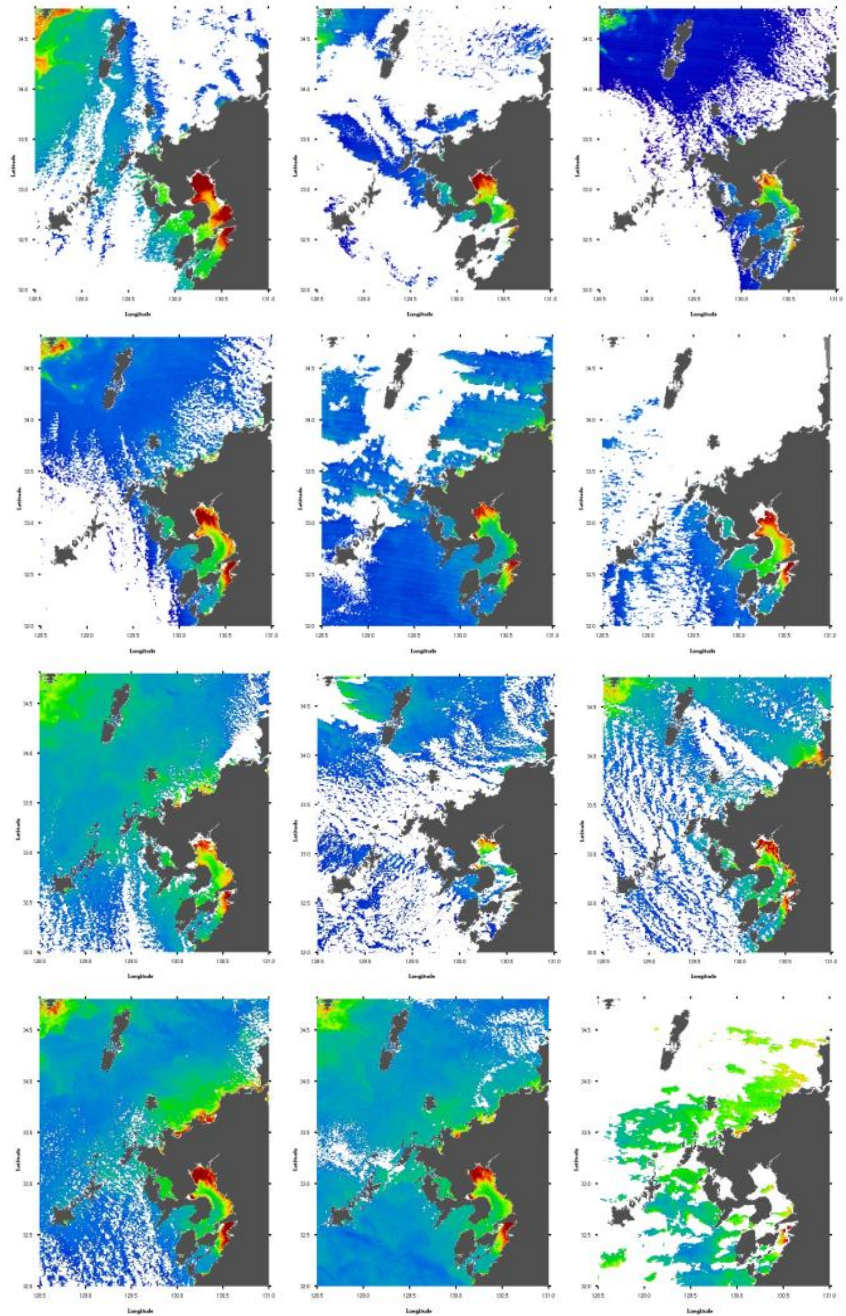

Fig. 4. MODIS data derived chlorophyll-a concentrations in 2013 
Fig.5 also shows MODIS data derived chlorophyll-a concentrations acquired in 2012. MODIS data are acquired on January $2,6,7,12,17,20,21,23,26,29,30$, and 31 , respectively (from top left to bottom right in Fig.5).
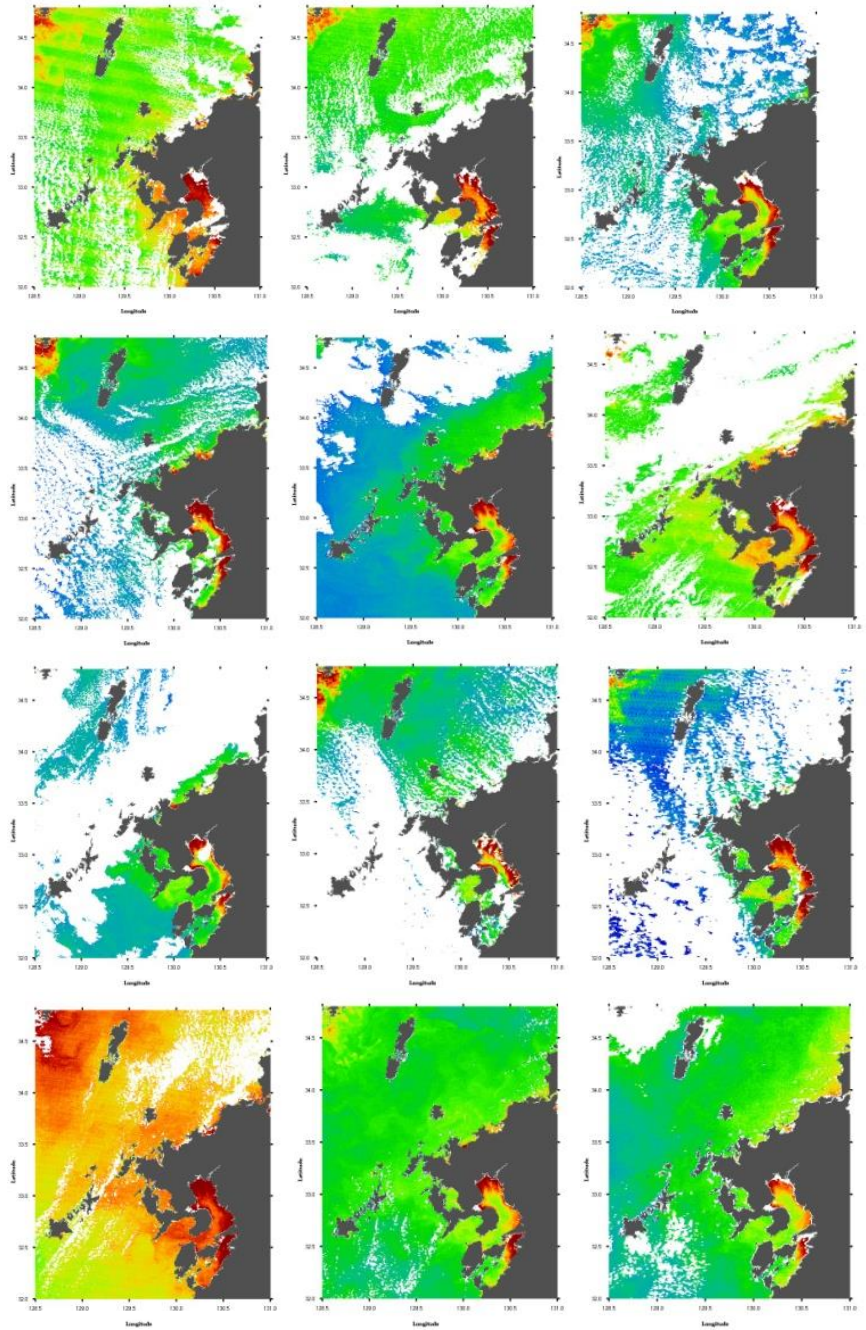

Fig. 5. MODIS data derived chlorophyll-a concentrations in 2012

Fig.6 shows the time series of MODIS data derived chlorophyll-a concentrations in 2011. MODIS data are acquired on January $1,2,7,8,14,17,22,26$, and 27, respectively (from top left to bottom right in Fig.6).
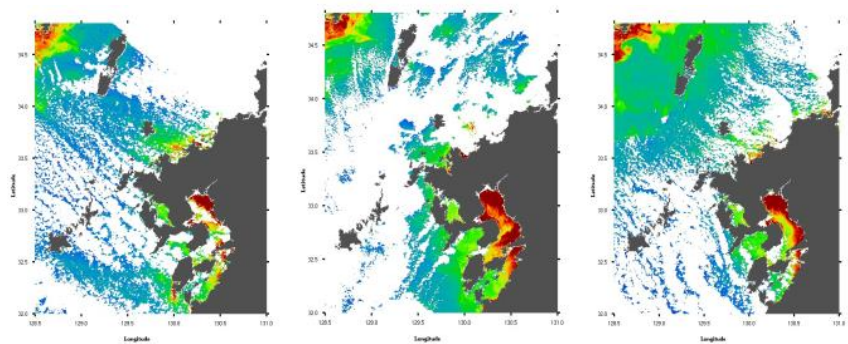
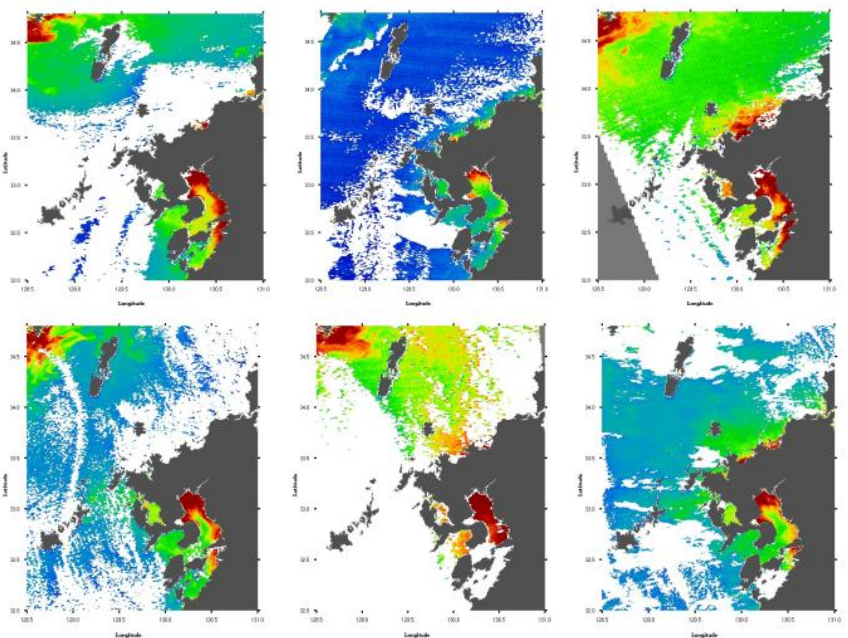

Fig. 6. MODIS data derived chlorophyll-a concentrations in 2011

Fig.7 shows the time series of MODIS data derived chlorophyll-a concentrations in 2011. MODIS data are acquired on January 1, 2, 9, 14, 16, 17, 18, 22, 24, 26, 27, 29, respectively (from top left to bottom right in Fig.7).
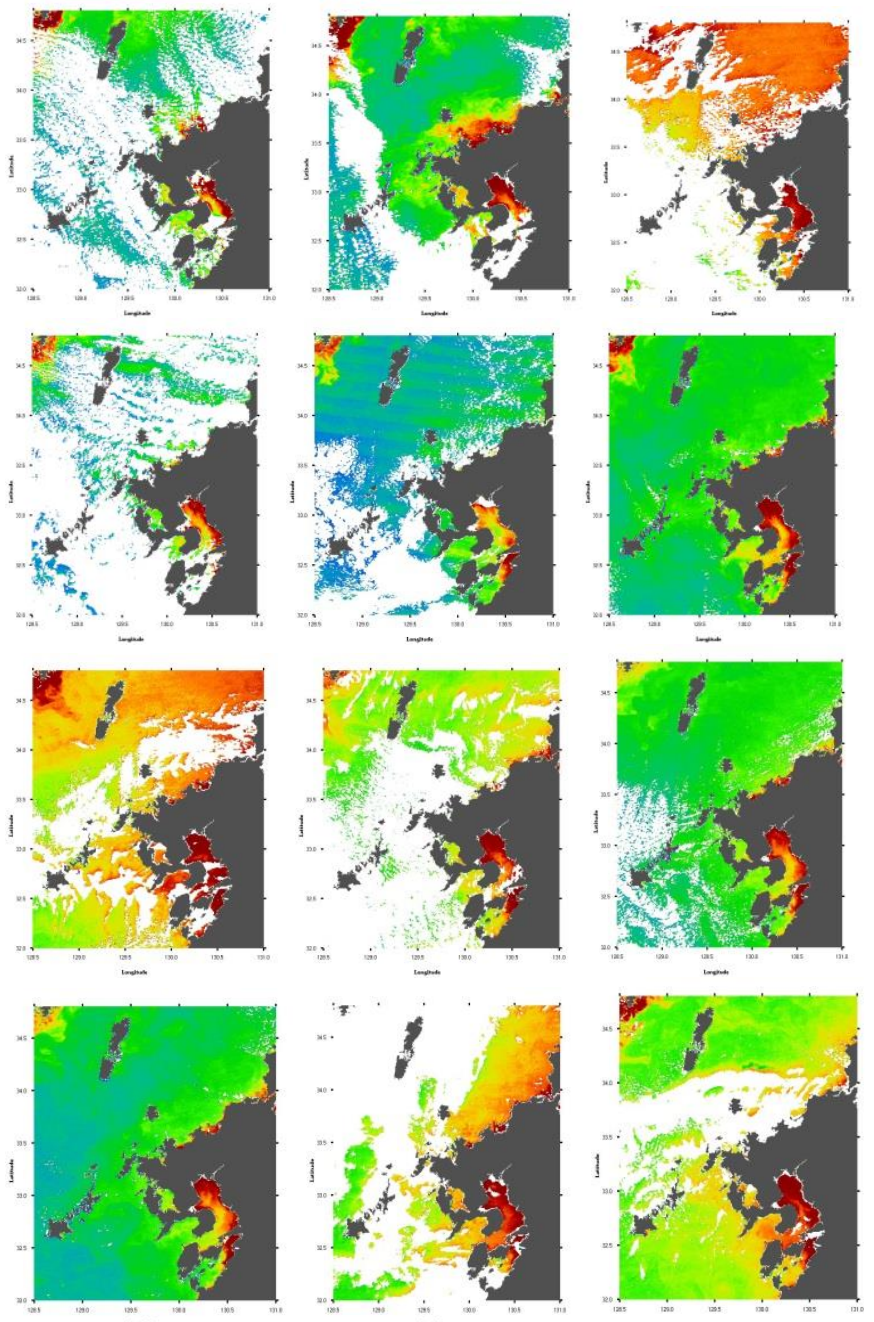

Fig. 7. MODIS data derived chlorophyll-a concentrations in 2010 
B. Trends of Chlorophyll-a Concentration in Ariake Bay Area as well as Tidal Hieght, Solar Direct Irradiation, and Wind Speed from North

Fig.8 (a) to (f) shows trends of chlorophyll-a concentration in Ariake Bay area as well as tidal height difference a day, solar direct irradiance and wind speed from the North in 2015, 2014, 2013, 2012, 2011 and 2010, respectively. Typical trend is that chlorophyll-a concentration is increased in accordance with the tidal height difference a day it is not always true though. The reason for this is the following, namely, (1) chlorophyll appears in around sea bottom because nutrition rich water is situated in around sea bottom, (2) chlorophyll moves up to sea surface due to tidal effect (from the neap to the spring tide).

This fact is not always true. For instance, chlorophyll is not increased at the spring tide (35 days in the begging of February in 2015 and 12 days in January in 2012). In such cases, wind speed from the north is relatively strong and solar irradiance is not so high. This implies that sea water is mixed up between sea surface and sea bottom due to convection caused by relatively strong wind. Also it is implied that sea surface temperature is not getting warm because solar irradiance is weak results in decreasing of chlorophyll-a concentration.

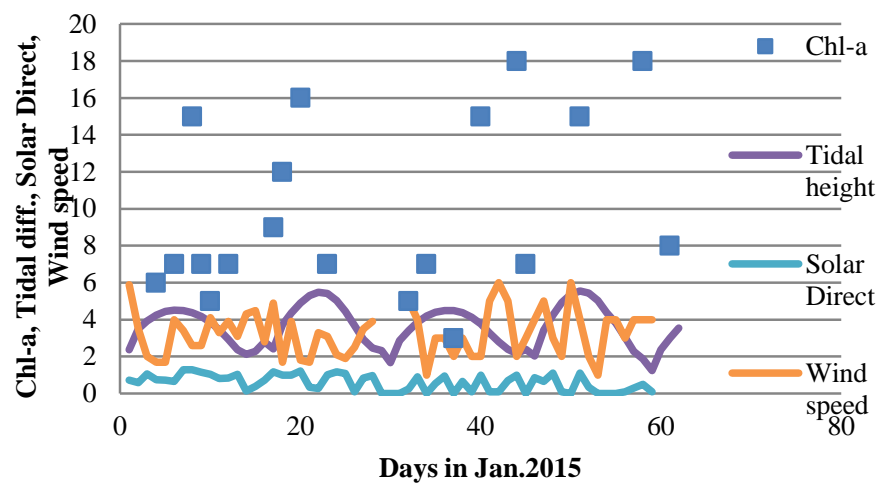

(a) 2015

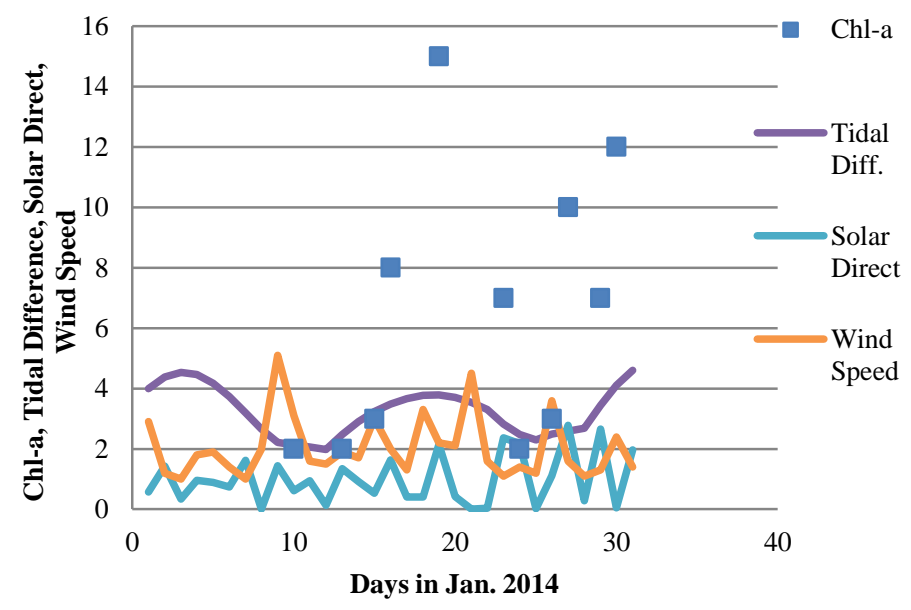

(b) 2014

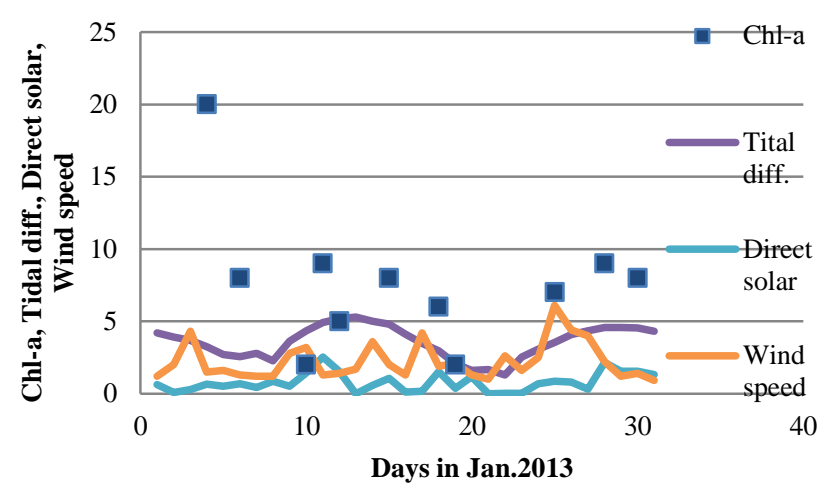

(c) 2013

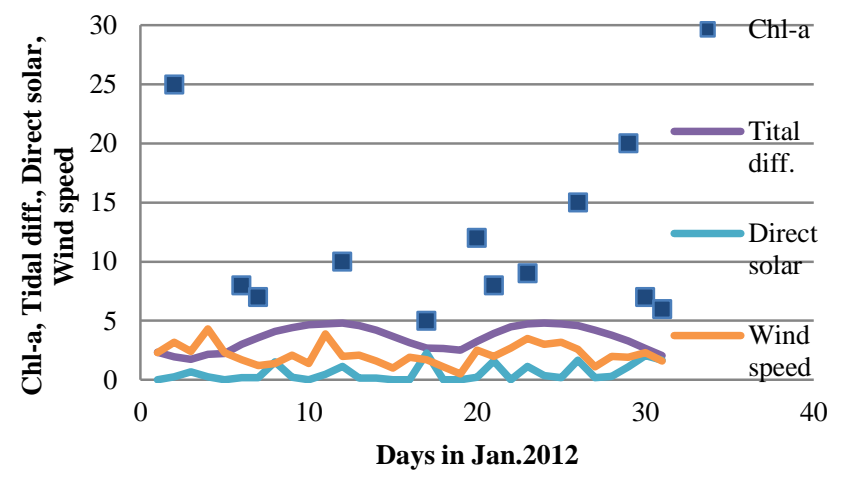

(d) 2012

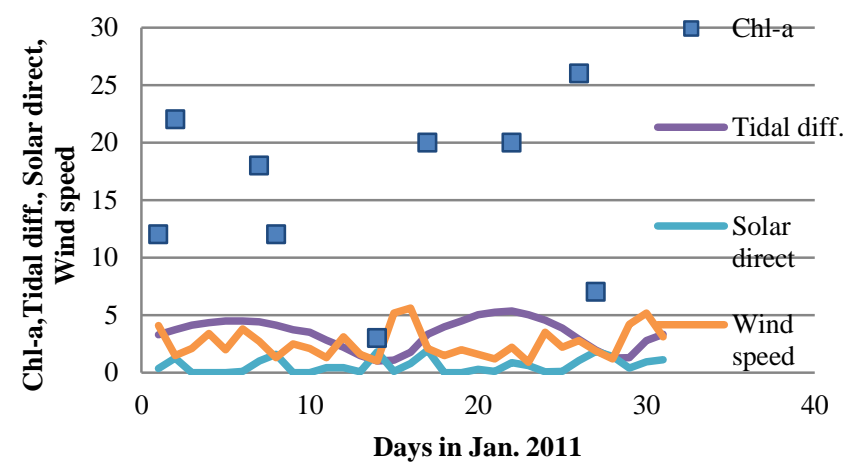

(e) 2011

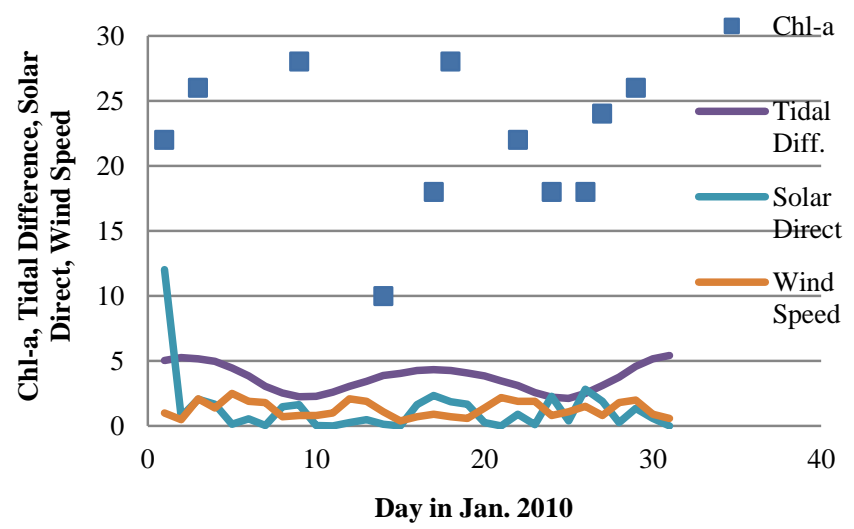

(f) 2010

Fig. 8. Trends of chlorophyll-a concentration in Ariake Bay area as well as tidal height, solar direct irradiance and wind speed from the North 


\section{Locality of Chlorophyll-a Concentration in Ariake Bay, \\ Isahaya Bay and Kumamoto Offshore Areas}

In order to make sure that the sources of the chlorophyllconcentrations of the three different sea areas, Ariake Bay, Isahaya Bay and Kumamoto Offshore are different each other, trends of chlorophyll-a concentration of three sea areas are compared. Fig.9 (a) to (f) shows the calculated trends for the year of 2010 to 2015 . Although these trends are very similar due to the fact that nutrition condition and weather condition are almost same in the Ariake Sea area, the chlorophyll-a concentrations of these sea areas shows somewhat different trends each other in detail. Therefore, it may say that the sources of the chlorophyll-a concentration are different.

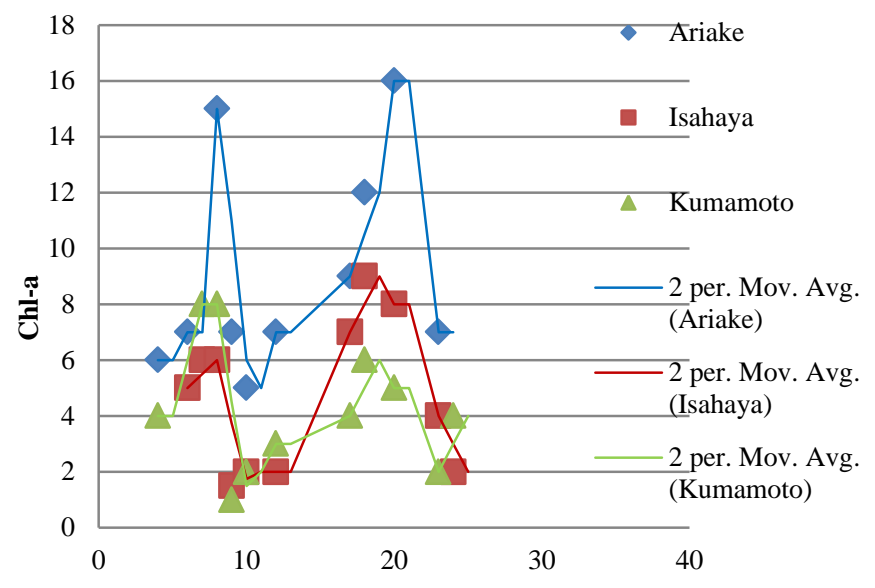

Days in Jan. 2015

(a) 2015

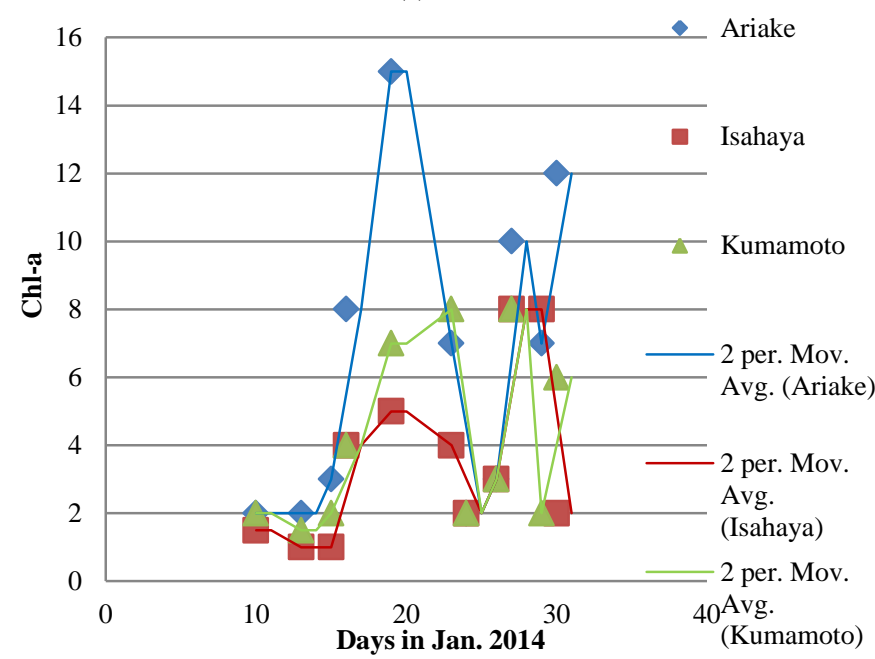

(b) 2014

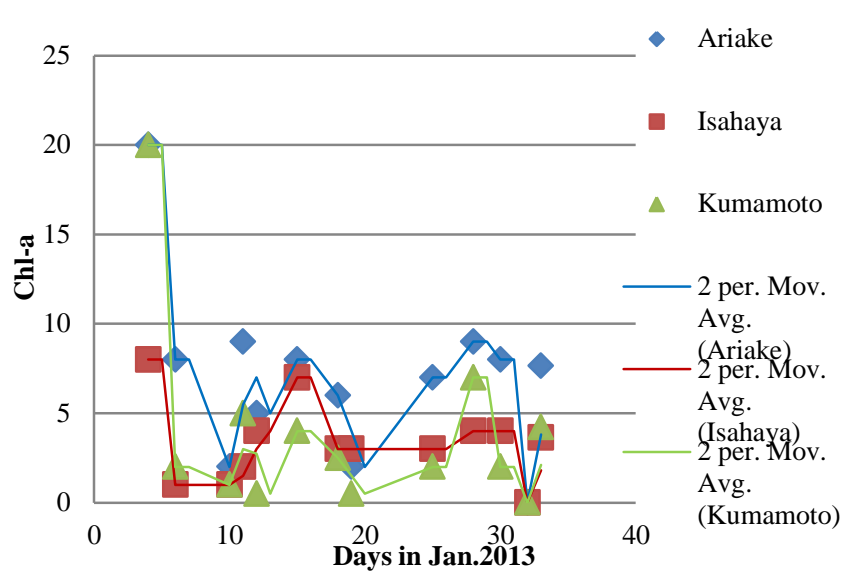

(c) 2013

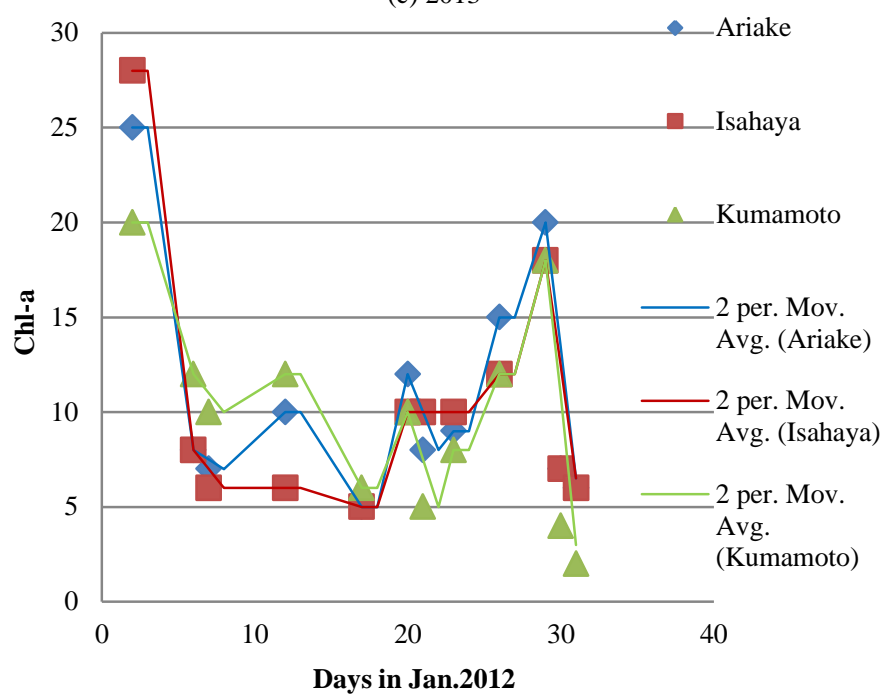

(d) 2012

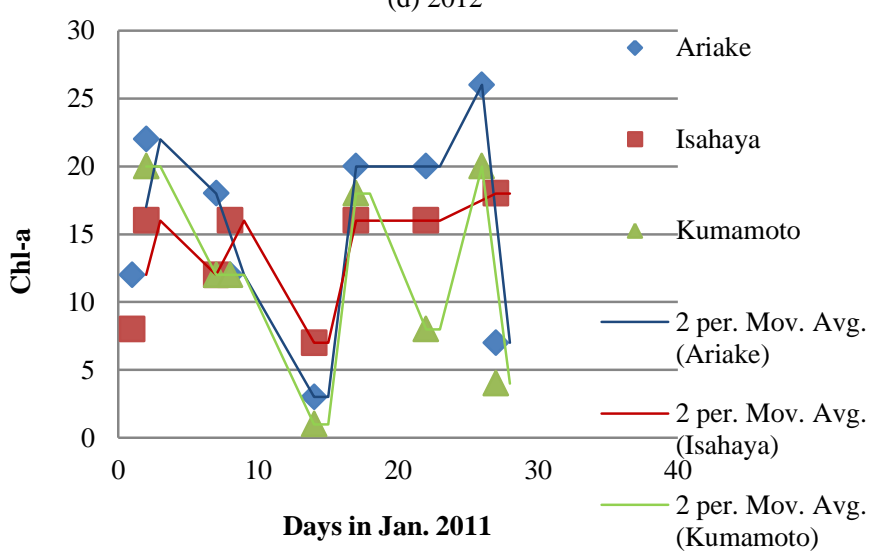

(e) 2011 


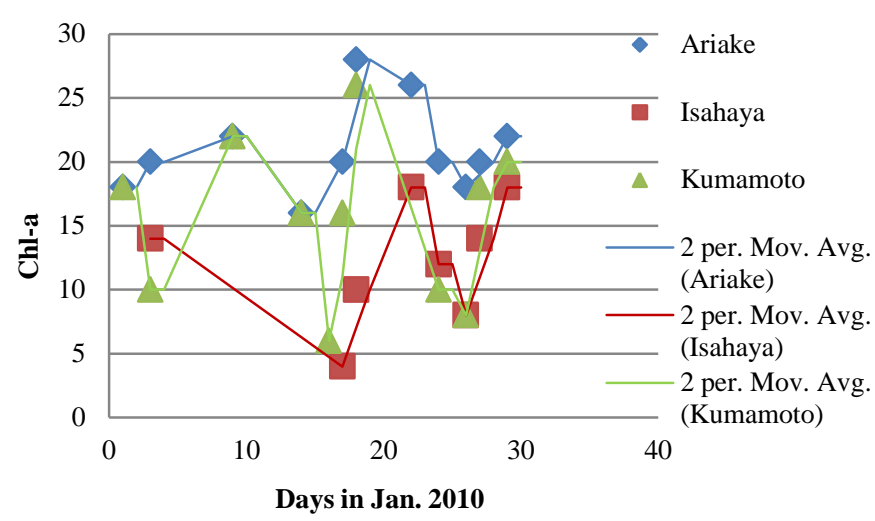

(f) 2010

Fig. 9. Trends of chlorophyll-a concentrations at three intensive test sites

As is mentioned before, these three trends are very similar due to the fact that nutrition condition and weather condition are almost same in the Ariake Sea area. Therefore, monthly mean of chlorophyll-a concentrations of three sea areas show almost same trends as shown in Fig. 10.

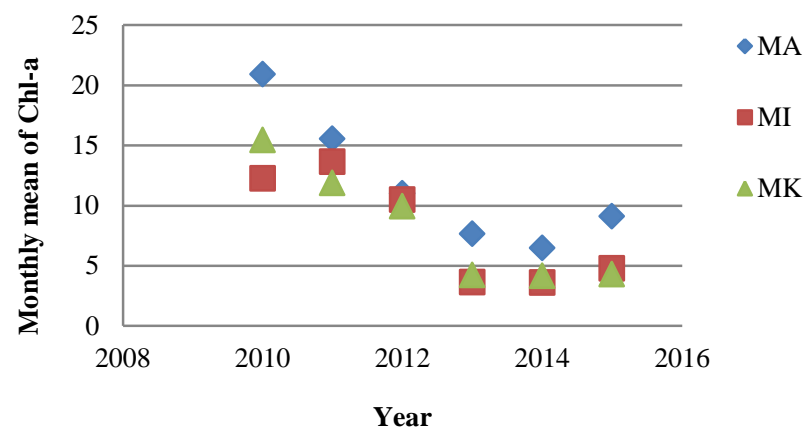

Fig. 10. Monthly mean of chlorophyll-a concentrations of three sea areas

Also, correlations of chlorophyll-a concentration of three different sea areas are very similar as shown in Fig.11.

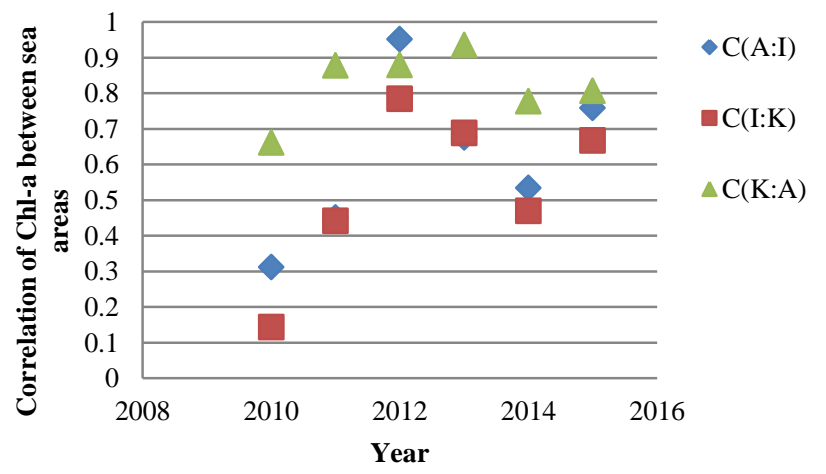

Fig. 11. Correlations of chlorophyll-a concentrations of three different sea areas

\section{Correlations Between Chlorophyll-a Concentration and Meteorological Conditions for Three Different Sea Areas}

Fig.12 shows the correlations between chlorophyll-a concentration and the meteorological conditions, tidal difference a day, solar irradiance, wind speed from the north.

Correlation coefficients are calculated between chlorophyll-a concentration and the other data of tidal difference a day, sun shine time duration a day and wind speed from the north. The result shows that there is a strong relation between chlorophyll-a concentration and tidal difference a day, obviously followed by wind speed from the north.

It is not always true. The situation may change by year by year. In particular, there is clear difference between year of 2011 and the other years, 2012 to 2015. One of the specific reasons for this is due to the fact that chlorophyll-a concentration in 2011 is clearly greater than those of the other years. Therefore, clear relation between chlorophyll-a concentration and the other data of tidal difference a day, sun shine time duration a day and wind speed from the north cannot be seen. That is because of the fact that there is time delay of chlorophyll-a increasing after the nutrient rich bottom seawater is flown to the sea surface.

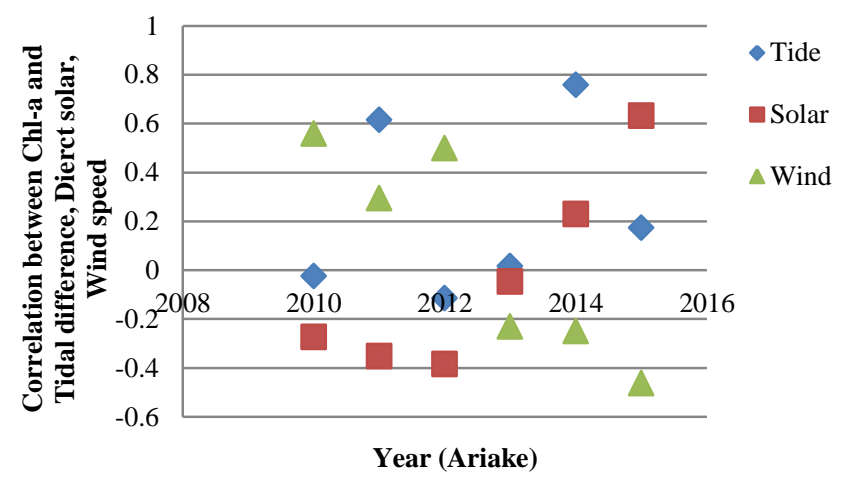

(a) Ariake

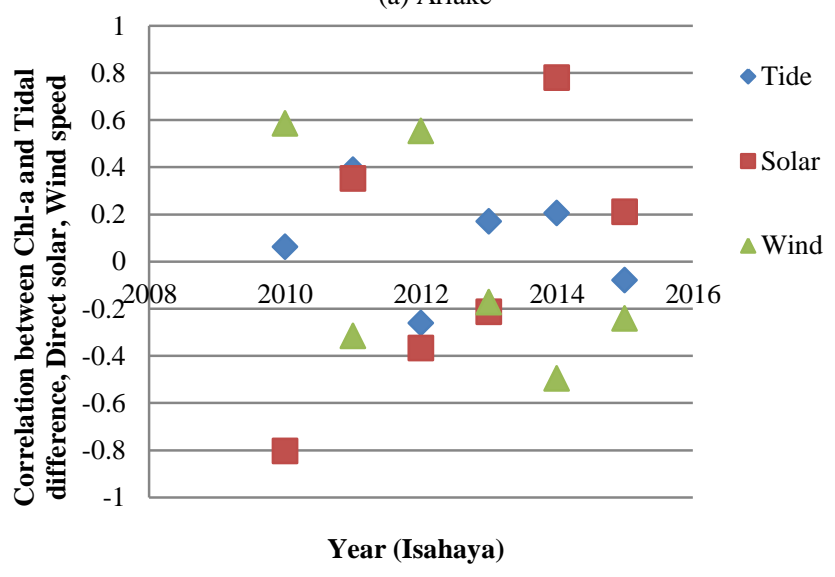

(b) Isahaya 


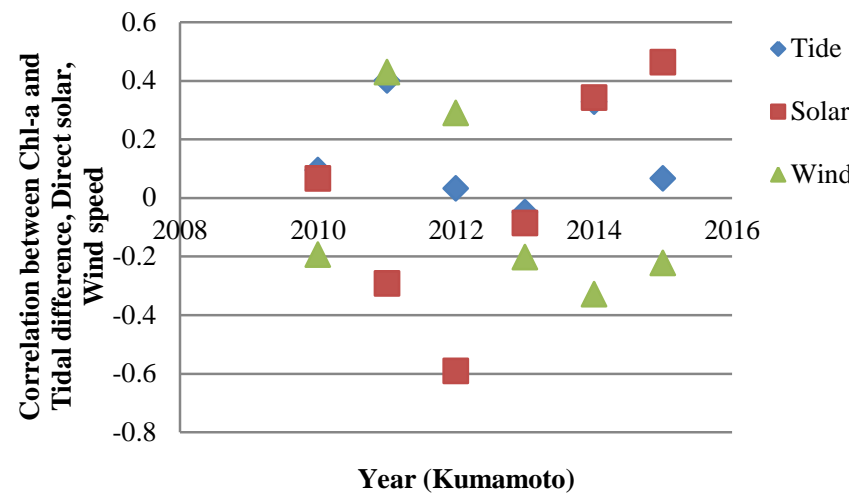

(c) Kumamoto

Fig. 12. Correlations between chlorophyll-a concentration and the meteorological conditions

\section{CONCLUSION}

Through experiments with Terra and AQUA MODIS data derived chlorophyll-a concentration and meteorological data and tidal data which are acquired for 6 years (winter 2010 to winter 2015), it is found that strong relation between the chlorophyll-a concentration and tidal height changes. Also it is found that the relations between ocean wind speed and chlorophyll-a concentration. Meanwhile, there is a relatively high correlation between sunshine duration a day and chlorophyll-a concentration.

It is found that strong correlation between the truth data of chlorophyll-a and MODIS derived chlorophyll-a concentrations with $\mathrm{R}$ square value ranges from 0.677 to 0.791 . Also, there is relatively low chlorophyll-a concentration sea area between Isahaya Bay and Ariake Bay. Therefore, chlorophyll-a concentration variation are isolated between both sea areas. Meantime, chlorophyll-a concentrations of Isahaya Bay, Ariake Bay and Kumamoto Offshore are different each other. It seems that chlorophyll-a concentrations at Isahaya Bay, Kumamoto Offshore and Ariake Bay are originated from the mouth of rivers while that of Kumamoto Offshore is migrated from the south.

\section{ACKNOWLEDGMENT}

The authors would like to thank Dr. Toshiya Katano of Tokyo University of Marine Science and Technology, Dr. Yuichi Hayami, Dr. Kei Kimura, Dr. Kenji Yoshino, Dr. Naoki Fujii and Dr. Takaharu Hamada of Institute of Lowland and Marine Research, Saga University for their great supports through the experiments.

\section{REFERENCES}

[1] Yuji Ito, Toshiya Katano, Naoki Fujii, Masumi Koriyama, Kenji Yoshino, and Yuichi Hayami, Decreases in turbidity during neap tides initiate late winter large diatom blooms in a macrotidal embayment, Journal of Oceanography,69: 467-479. 2013.

[2] Nishikawa T (2002) Effects of temperature, salinity and irradiance on the growth of the diatom Eucampia zodiacus caused bleaching seaweed
Porphyra isolated from Harima-Nada, Seto Inland Sea, Japan. Nippon Suisan Gakk 68: 356-361. (in Japanese with English abstract)

[3] Nishikawa $T$ (2007) Occurrence of diatom blooms and damage tocultured Porphyra thalli by bleaching. Aquabiology 172: 405-410. (in Japanese with English abstract)

[4] Nishikawa T, Hori Y (2004) Effects of nitrogen, phosphorus and silicon on the growth of the diatom Eucampia zodiacus caused bleaching of seaweed Porphyra isolated from Harima-Nada, Seto Inland Sea, Japan. Nippon Suisan Gakk 70: 31-38. (in Japanese with English abstract)

[5] Nishikawa T, Hori Y, Nagai S, Miyahara K, Nakamura Y, Harada K, Tanda M, Manabe T, Tada K (2010) Nutrient and phytoplankton dynamics in Harima-Nada, eastern Seto Inland Sea, Japan during a 35year period from 1973 to 2007. Estuaries Coasts 33: 417-427.

[6] Nishikawa T, Hori Y, Tanida K, Imai I (2007) Population dynamics of the harmful diatom Eucampia zodiacus Ehrenberg causing bleachings of Porphyra thalli in aquaculture in Harima- Nada, the Seto Inland Sea, Japan. Harmful algae 6: 763-773.

[7] Nishikawa T, Miyahara K, Nagai S (2000) Effects of temperature and salinity on the growth of the giant diatom Coscinodiscus wailesii isolated from Harima-Nada, Seto Inland Sea, Japan. Nippon Suisan Gakk 66: 993-998. (in Japanese with English abstract)

[8] Nishikawa T, Tarutani K, Yamamoto T (2009) Nitrate and phosphate uptake kinetics of the harmful diatom Eucampia zodiacus Ehrenberg, a causative organism in the bleaching of aquacultured Porphyra thalii. Harmful algae 8: 513-517.

[9] Nishikawa T, Yamaguchi M (2006) Effect of temperature on lightlimited growth of the harmful diatom Eucampia zodiacus Ehrenberg, a causative organism in the discoloration of Porphyra thalli. Harmful Algae 5: 141-147.

[10] Nishikawa T, Yamaguchi $M$ (2008) Effect of temperature on lightlimited growth of the harmful diatom Coscinodiscus wailesii, a causative organism in the bleaching of aquacultured Porphyra thalli. Harmful Algae 7: 561-566.

[11] Syutou T, Matsubara T, Kuno K (2009) Nutrient state and nori aquaculture in Ariake Bay. Aquabiology 181: 168-170. (in Japanese with English abstract)

[12] Harada K, Hori Y, Nishikawa T, Fujiwara T (2009) Relationship between cultured Porphyra and nutrients in Harima-Nada, eastern part of the Seto Inland Sea. Aquabiology 181: 146-149. (in Japanese with English abstract)

[13] Arai K., T. Katano, Trend analysis of relatively large diatoms which appear in the intensive study area of the ARIAKE Sea, Japan, in winter (2011-2015) based on remote sensing satellite data, Internationa Journal of Advanced Research in Artificial Intelligence (IJARAI), 4, 7, to appear, 2015.

\section{AUTHORS PROFILE}

Kohei Arai, He received BS, MS and PhD degrees in 1972, 1974 and 1982, respectively. He was with The Institute for Industrial Science and Technology of the University of Tokyo from April 1974 to December 1978 also was with National Space Development Agency of Japan from January, 1979 to March, 1990. During from 1985 to 1987, he was with Canada Centre for Remote Sensing as a Post Doctoral Fellow of National Science and Engineering Research Council of Canada. He moved to Saga University as a Professor in Department of Information Science on April 1990. He was a councilor for the Aeronautics and Space related to the Technology Committee of the Ministry of Science and Technology during from 1998 to 2000. He was a councilor of Saga University for 2002 and 2003. He also was an executive councilor for the Remote Sensing Society of Japan for 2003 to 2005 . He is an Adjunct Professor of University of Arizona, USA since 1998. He also is Vice Chairman of the Commission "A" of ICSU/COSPAR since 2008. He wrote 34 books and published more thyan 510 journal papers. He is Edito-inChief of IJACSA and International Journal of Intelligent Systems and Applications. http://teagis.ip.is.saga-u.ac.jp/bib.htm 